\title{
Considerações sobre a política de avaliação da alfabetização: pensando a partir do cotidiano escolar
}

\author{
MARIA TERESA ESTEBAN
}

Universidade Federal Fluminense

As políticas públicas devem zelar pelo bem viver das crianças, garantindo-lhes as condições necessárias a um desenvolvimento pleno e feliz; e a aprendizagem delas deve ser, sem qualquer dúvida, a principal preocupação da escola. É claro que essa é uma compreensão, entre outras que se entrecruzam na dinâmica social. Objetivamente, as políticas públicas para a infância expressam, entre tensões e controvérsias, o compromisso da sociedade com suas crianças, sendo a educação, que não se esgota na escolarização, uma das evidências das opções feitas. Um olhar atento sobre nossa vida cotidiana indica o quanto nós, sociedade brasileira, temos sido pouco cuidadosos com nossas crianças, o que baliza o funcionamento da escola e os percursos infantis nos processos de escolarização, embora a ele não se limite.

Neste artigo, trago as políticas de avaliação da alfabetização para refletir sobre os sentidos que a avaliação vem adquirindo no contexto das políticas públicas. As relações estabelecidas entre os processos instaurados e resultados obtidos nas esferas macro e microestruturais tornam necessária a indagação das relações que se produzem entre as políticas instituídas e a construção de processos favoráveis às aprendizagens de todas as crianças. Essa mantém-se uma questão prioritária, pois ainda não conseguimos garantir a todas as crianças as aprendizagens escolares a que têm direito.

Os resultados insatisfatórios funcionam como catalisadores dos debates sobre educação. $\mathrm{O}$ reconhecimento do baixo rendimento dos estudantes conduz o modo como a escolarização se incorpora à agenda política nacional e demarca o debate sobre a avaliação educacional no Brasil, do qual a avaliação da aprendizagem infantil é parte. Como resposta à insuficiência verificada, propõe-se um modelo de avaliação educacional calcado na definição de metas, que dá visibilidade às políticas públicas em educação e pode envolver as dimensões qualitativa e quantitativa da avaliação. As metas atuam como um elo entre os parâmetros que fundamentam a avaliação e a realização cotidiana da prática pedagógica, com impacto inclusive na regulação das relações interpessoais. 
A proposição de processos avaliativos ancorados em parâmetros predefinidos e com pouca flexibilidade é indispensável à diferenciação dos sujeitos. $O$ padrão estabelece o que se considera normal, o que o torna também normativo, funcionando muitas vezes como uma imposição. Nesse sentido, avaliar apresenta-se como o ato em que se reconhece o que está dentro da norma, que resulta em um valor positivo, e o que dela se afasta, desqualificado por não corresponder aos parâmetros assumidos como válidos. Portanto, pode-se propor a avaliação qualitativa segundo esses pressupostos e a ela conferir uma função reguladora, para criar compatibilidade entre os sujeitos, seus discursos e seus percursos e a norma vigente, o que produz justificativas aceitáveis e socialmente válidas para a exclusão decorrente do fracasso escolar.

A dinâmica escolar demanda atenção à sua complexidade. As determinações que emanam das políticas públicas, os sujeitos diretamente envolvidos nos procedimentos escolares e seus saberesfazeres vinculam-se no que frequentemente emerge como desempenho escolar. Essas intrincadas relações entre os contextos escolar e social são reconhecidas no discurso oficial, que expõe com clareza a existência desses vínculos na produção dos resultados escolares, especialmente quando se trata de fracasso. Porém, há muitos modos de compreender essas relações, e no que se refere à avaliação da aprendizagem nem sempre se rompe com a perspectiva seletiva e excludente que orienta $o$ projeto hegemônico de educação escolar.

A atual política de avaliação da alfabetização destaca-se como um dos programas de ação altamente regulatórios. Proponho-me discuti-la focalizando a Provinha Brasil, exame nacional aplicado no $2^{\circ}$ ano do ensino fundamental, que visa monitorar a alfabetização realizada nas escolas públicas brasileiras, por meio da realização de uma avaliação diagnóstica do nível de desempenho das crianças, a fim de garantir que todos os estudantes se alfabetizem até os 8 anos de idade. A reflexão que apresento tem como referência o cotidiano escolar, com base no diálogo que venho mantendo com professoras atuando nos três anos iniciais do ensino fundamental, em escolas públicas que recebem predominantemente crianças das classes populares. Esse diálogo com as professoras em diversos contextos e minhas observações fizeram emergir a Provinha Brasil como um objeto relevante de estudo.

Os dois projetos de pesquisa ${ }^{1}$ que desenvolvo dão suporte a esse trabalho e demarcam opções feitas neste artigo. Ambos têm como principais referências a pesquisa com o cotidiano da escola pública (Garcia, 2003) e a pesquisa-ação participativa (Fals Borda, 1983), permitindo um diálogo permanente com os sujeitos que compõem a escola pública e uma reflexão compartilhada com docentes envolvidas na pesquisa. Essa metodologia possibilita ter a experiência da sala de aula junto com a professora e as crianças e viver um fecundo intercâmbio com várias professoras por meio do estudo e da reflexão coletiva sobre a avaliação no cotidiano escolar.

1 Um projeto desenvolve-se com um grupo de estudos sobre avaliação nos anos iniciais de escolarização, composto por professoras atuando em escolas públicas em três municípios diferentes, orientadoras pedagógicas e estudantes da Faculdade de Educação da Universidade Federal Fluminense (UFF). Com o outro projeto, acompanho o cotidiano de uma escola pública, com participação em reuniões pedagógicas e em uma das turmas de $1^{\circ}$ ciclo. $\mathrm{O}$ trabalho conta com apoio do Conselho Nacional de Desenvolvimento Científico e Tecnológico (CNPq) e da Fundação de Amparo à Pesquisa do Estado do Rio de Janeiro (FAPERJ). 


\section{CONTROVÉRSIAS}

A escola pública brasileira tem passado por mudanças significativas nas últimas décadas, com ampliação do número de estudantes e gradual redução dos índices de evasão e repetência, o que contribui para que mais tempo na escola se traduza em conclusão de mais anos escolares. Esses resultados, observados especialmente no ensino fundamental, são efeito de um conjunto variado de ações derivadas de políticas públicas voltadas ao acesso à escolarização. Porém, há sérios problemas em relação à aprendizagem dos estudantes, como demonstra a alta taxa de distorção idade-série verificada. ${ }^{2}$ A implantação de um sistema de avaliação baseado em exames estandardizados é uma das propostas oficiais visando à melhoria da qualidade da educação brasileira.

Os processos que produzem a democratização do acesso à escola se vinculam à histórica luta das classes populares por escolarização. Portanto, as conquistas obtidas são em parte tributárias dos movimentos populares e constituem-se nos marcos das disputas e dos acordos socialmente produzidos. E preciso atenção permanente para as conquistas não se diluírem em processos pouco favoráveis a esses grupos sociais.

A ampliação das vagas nas escolas públicas brasileiras se faz acompanhar de duas importantes modificações em sua estrutura: 1) o crescente ingresso no magistério de profissionais oriundos das classes populares, com impacto na definição do perfil sociocultural das professoras e dos professores; e 2) o crescimento do número de unidades escolares na periferia urbana, provocando a inserção da escola em novos contextos.

Esses processos não são meramente quantitativos, compõem movimentos socioeconômicos e culturais que introduzem novas questões à escolarização e demandam/ produzem reformulação em suas práticas cotidianas. A presença do popular na escola, pelos novos sujeitos que dela participam e pelos novos contextos dos quais se torna parte, redesenha suas feições e exige que a escola re-conheça, re-defina e re-signifique suas práticas e seus sentidos. Uma transformação profunda se faz necessária e tem sua maior expressão na constatação de que as crianças das classes populares têm ampliadas suas possibilidades de frequentar a escola, embora a escola continue thes oferecendo poucas possibilidades de acesso ao conhecimento.

A inserção socioeconômica dos estudantes, no Brasil, condiciona fortemente os resultados escolares (IBGE, 2010). Essa evidência não pode ser negada, porém, muitas vezes camufla o confronto intercultural que os resultados insatisfatórios abrigam. As novas configurações que a escola e a sala de aula adquirem ressaltam sua constituição como contextos pluri-interculturais, complexos, enquanto o processo de escolarização se rege por um projeto educacional monocultural. Nessa tensão inscreve-se o ambivalente projeto de democratização da escola brasileira: nas propostas oficiais e nas práticas cotidianas, há o discurso explícito de defesa de todos na escola, embora suas entrelinhas abriguem discursos ocultos de manutenção do conhecimento como privilégio de poucos. Frequentemente as ações se vinculam a dispositivos que asseguram a desigualdade na socialização e validação

2 Segundo o Instituto Nacional de Estudos e Pesquisas Educacionais Anísio Teixeira (INEP), em 2010 verificava-se, no ensino público, uma taxa de distorção idade-série de $35,7 \%$ no $6^{\circ}$ ano, de $28,5 \%$ no $9^{\circ}$ ano e de $47,5 \%$ ao final do ensino médio. Disponível em: <http://portal.inep.gov.br/indicadores-educacionais>. Acesso em: 20 dez. 2011. 
do conhecimento, o que exige cuidado com os efeitos das propostas pedagógicas implementadas sobre as aprendizagens dos estudantes, especialmente os das classes populares.

O discurso oficial, apoiado na necessidade de melhorar a qualidade da educação, propõe a avaliação fundamentalmente como um mecanismo de controle, direcionado à mensuração do desempenho dos estudantes por meio de exames em larga escala. $\mathrm{A}$ busca de uma medida objetiva, capaz de expressar de modo claro e neutro o nível de desempenho, orienta a formulação de procedimentos cujas preocupações são eminentemente técnicas. A mensuração aliada ao estabelecimento de metas sustenta processos de avaliação mais vinculados à gestão educacional do que à aprendizagem infantil.

Tal articulação demanda profunda reflexão e amplo debate sobre o que se considera qualidade da educação, pois o cumprimento de metas e elevação de índices de desempenho não expressam necessariamente uma efetiva ampliação dos conhecimentos pelos estudantes ou uma ruptura com os mecanismos de produção das desigualdades escolares. A clara relação entre a dinâmica sociocultural e os processos de produção dos resultados escolares leva à problematização das propostas que reduzem o papel das dimensões ética, política, social, econômica e cultural na articulação das políticas públicas e valorizam a homogeneidade, desconsiderando processos subjetivos e condições objetivas articulados na aprendizagem e no ensino.

A política de avaliação apresenta-se como meio para se alcançar melhor qualidade na educação brasileira, porém se fundamenta na redução de seu sentido e na simplificação nas análises sobre a produção dos resultados escolares. Ao simplificar processos complexos, retira da reflexão e do debate aspectos indispensáveis à ação escolar, aos processos de aprendizagem, aos projetos de ensino e aos posicionamentos dos sujeitos em relação a seus resultados globalmente considerados, não apenas sujeitos hierarquicamente posicionados segundo seus desempenhos. Simultaneamente, sua intenção de neutralidade e objetividade não se realiza, pois a técnica não é suficiente para eliminar a dimensão sociocultural do conhecimento, dos processos de sua socialização e validação ou mesmo das dinâmicas de aprendizagem.

A avaliação, assim proposta, constrói-se por meio de procedimentos de aferição que provocam distorções em seus resultados. Segundo Stobart (2010, p. 164):

Formulaba [a Assessment of Performance Unit] la misma pregunta de tres maneras y obtenía unos niveles muy diferentes de respuestas correctas.

Três más 14 son __ ( $97 \%$ de respuestas correctas).

¿Qué número es tres más que 14? (67\% de respuestas correctas)

¿ Qué número supera a 14 en três unidades? (54\% de respuestas correctas)

Una prueba nacional solo puede preguntar eso de una manera: en consecuencia, ¿qué nos diría respecto a cómo entienden la adición?

Complementando:

Paul Newton ha examinado las consecuencias de informa del error de medida en un sistema que considera que las puntuaciones son precisas y exactas. Dada la fiabilidad conocida de un testm mi puntuación de 45 podría representar, por ejemplo, una "puntuación verdadera" (una inútil expresión estadística) entre 41 y 49. El problema 
es que mi 45 puede situarme en un nivel 4 pero no la puntuación 44. Por eso Dylan William (2001) estimaba que en los tests nacionales, al menos, el 30\% de los alumnos están erróneamente clasificados. (idem, p. 166)

Como a literatura no campo da avaliação vem mostrando há décadas (Fernandes, 2009; Santos Guerra, 2003; Saul, 1991; entre outros), a reflexão sobre a avaliação precisa incorporar suas múltiplas dimensões e as questões relativas ao ensino, à aprendizagem e à concepção de infância que se entrelaçam na composição da vida escolar. A estas devem somar-se outras, relativas aos processos sociais, com as características peculiares a cada sociedade. Portanto, em sociedades mestiças como a brasileira, no centro da reflexão sobre a ação escolar deve estar a diferença cultural, com seus desdobramentos na produção da heterogeneidade constituinte da sala de aula. Tais questões não são externas à prática pedagógica; como produções social, histórica e cultural atuam na configuração dos múltiplos percursos, relações e conhecimentos vividos pelos sujeitos. Compõem o cotidiano escolar, em que as relações de poder se vinculam, em contextos intra e extraescolares, à criação de espaços mais ou menos abertos a negociações, rupturas, reinvenções e redefinições, atravessados por possibilidades e tensões resultantes dos encontros entre movimentos fluidos e flexíveis e prescrições rígidas, característicos dos processos educacionais.

Apesar das críticas recorrentes, a concepção classificatória de avaliação mantém-se mesmo em algumas propostas que ressaltam a prioridade dos procedimentos qualitativos de avaliação, em especial da aprendizagem infantil. A ênfase na dimensão qualitativa, em muitos documentos oficiais inclusive, não retira do processo seus aspectos seletivo e excludente, que se podem sustentar tanto em dados quantitativos quanto em qualitativos. Sua articulação refere-se aos instrumentos e procedimentos usados e, sobretudo, aos padrões que suportam as práticas empreendidas, construídos de acordo com modelos - de sujeito, de criança, de aprendizagem, de ensino, enfim, de vida - idealizados e considerados universais.

Observações no cotidiano escolar, aliadas a estudos sobre avaliação educacional, demonstram não bastar a eficiência técnica: é indispensável redefinir os sentidos dos processos de avaliação. Sem alterar o sentido classificatório da avaliação, modificam-se apenas os modos de produção e de expressão da exclusão de muitos do direito ao acesso ao conhecimento, que continuam presentes nas práticas escolares, mesmo quando se elevam os índices de desempenho.

\section{REDUÇÕES}

Essas questões adquirem traços específicos nos distintos exames que compõem as avaliações oficiais. Os documentos relativos à Provinha Brasil trazem essa simplificação na configuração de seus dois termos fundamentais: avaliação e alfabetização. A avaliação por articular-se pela mensuração do desempenho da criança em um exame estandardizado, e a alfabetização por reduzir-se ao "processo de apropriação da tecnologia da escrita pela criança” (CEALE, 2008, p. 12); estimula-se o ensino das convenções do código escrito e deixa-se em segundo plano a aprendizagem da linguagem escrita.

A avaliação é uma atividade social, inscrita na dinâmica cultural, portanto, impossível de adquirir sentido fora da cultura dos sujeitos que dela participam. Vista como 
descrição objetiva dos sujeitos de acordo com modelos predeterminados, em virtude de níveis de desempenho alcançados em provas estandardizadas, a avaliação fortalece a perspectiva classificatória, com seus matizes de exclusão e seletividade, e diminui a visibilidade dos fenômenos complexos que se entrelaçam aos resultados aferidos.

Do mesmo modo, é insuficiente considerar a alfabetização como mero domínio de um código e secundarizar a preocupação com os sentidos que percorrem a escrita, como produção humana. Alfabetização é necessariamente parte das relações socioculturais em que os múltiplos textos se configuram e nas quais os sujeitos dialogam com seus sentidos. A escrita existe como prática intersubjetiva.

Em síntese, no atual modelo, a avaliação resume-se a exame, e alfabetização a aquisição de convenções do código escrito. Ambos os conceitos são esvaziados em consonância com as exigências, dos exames em larga escala, de produção e manipulação de dados mais precisos e simplificados. Tal operação reflete o aligeiramento da noção de sujeito presente na concepção de educação que baliza a política de avaliação.

A ênfase na proficiência dos estudantes nos exames dificulta a reflexão sobre os múltiplos percursos de aprendizagem infantil ao validar apenas as trajetórias que estão em conformidade com as descrições existentes nos documentos que orientam a aplicação e a análise da "provinha". O exame resulta em um diagnóstico, que se orienta por níveis de alfabetização previamente estabelecidos (Brasil, 2011, p. 14).

O enquadramento necessário ao diagnóstico proposto desvitaliza e descontextualiza os estudantes, no que se refere à sua experiência sociocultural e às características da dinâmica aprendizagem-ensino na qual se inserem. As aprendizagens e os conhecimentos se traduzem em competências, indicadores, gráficos e dados, ou seja, fragmentos quantificáveis que em muito se distanciam das relações que cada sujeito efetivamente estabelece com a cultura escrita. Esse sujeito ressignificado retorna à sala de aula como a apresentação precisa do que cada estudante é, a partir da constatação do que cada um sabe dentro de uma prova reconhecidamente reduzida e redutora.

A Provinha Brasil expressa a redução do educacional ao campo estritamente técnico-pedagógico, rompendo os vínculos com as questões sociais e culturais presentes na vida escolar. Sobre essa redução opera-se outra, pois as questões da prova tratam de apenas uma parte das habilidades selecionadas como indispensáveis ao processo de alfabetização, conforme informação existente no kit Provinha Brasil (Brasil,2009, p. 11-12).

As provas estandardizadas não realizam uma avaliação da aprendizagem, elas aferem o desempenho nas habilidades previamente selecionadas como fundamentais para a leitura e escrita, por meio de um teste objetivo. Os estreitos e rígidos limites do exame delimitam as habilidades que serão verificadas. Entre os cinco eixos considerados imprescindíveis para o desenvolvimento da alfabetização e do letramento no documento citado - apropriação do sistema de escrita; leitura; escrita; compreensão e valorização da cultura escrita; desenvolvimento da oralidade -, apenas os dois primeiros são efetivamente incorporados à Provinha.

A avaliação de caráter quantitativo e classificatório, realizada por intermédio de procedimentos de mensuração de fragmentos do comportamento que podem ser observáveis, volta a ganhar relevância, embora não sejam recentes as críticas a essa modalidade. Destaco o trabalho de Díaz Barriga (1999), que analisa o processo de redução da avaliação educacional a exame, no qual as práticas escolares se colocam a serviço das funções de 
credenciamento e controle, produzindo, segundo sua denominação, uma "pedagogia do exame" que organiza as práticas cotidianas em conformidade às características dos instrumentos aos quais os estudantes serão submetidos. As atividades de ensino direcionam-se fundamentalmente pelos conteúdos que serão verificados e priorizam a preparação dos estudantes para os testes padronizados.

O autor, em sua severa crítica ao exame, ajuda-nos a percebê-lo como dispositivo do poder disciplinar (Foucault, 1997), constituído pela relação hierárquica que dá visibilidade, vigia e sanciona os sujeitos para normalizá-los, submetê-los e direcionar seu comportamento e seu rendimento de acordo com as demandas do modelo hegemônico de sociedade. Díaz Barriga denuncia o produtivismo que orienta a política de avaliação da educação e apresenta o teste objetivo, modalidade amplamente utilizada nos exames em larga escala, como um artefato do exame.

Tal compreensão do processo contribui para a percepção dos modos como o exame fragmenta e desvitaliza o conhecimento com o objetivo de garantir uniformidade, neutralidade e objetividade na coleta, correção e interpretação dos dados. Considerando a Provinha Brasil, tais procedimentos incidem sobre a linguagem, com a compreensão que o somatório das habilidades verificadas produz um sujeito alfabetizado. Porém, fraturada e descontextualizada, dificilmente a linguagem escrita será aprendida em sua complexidade ou poderão os conhecimentos a seu respeito ser avaliados, especialmente no início do processo de apropriação da escrita.

As respostas dos alunos podem ser interpretadas estabelecendo-se uma relação entre o número ou a média de acertos de um ou mais alunos e sua correspondência com níveis de desempenho descritos para a Provinha Brasil. Dessa forma, quando a criança consegue responder corretamente a um quantitativo de questões do teste, ela demonstra ter desenvolvido determinadas habilidades. (Brasil, 2011, p. 17)

O desempenho no exame leva a criança a ser enquadrada em um dos cinco níveis, o que se assume como evidência do "momento do processo de alfabetização em que as crianças se encontram, mas também como referência daquilo que é esperado em termos de progressão ao longo dos dois primeiros anos do ensino fundamental" (idem, ibidem). Portanto, os resultados afetam o modo como a criança é vista no presente e as expectativas que se criam sobre sua aprendizagem e seu desenvolvimento. A classificação frequentemente atua, ainda que algumas vezes indiretamente, como justificativa para a exclusão implícita no processo.

O trabalho de Gimeno Sacristán (1997) também contribui com essa reflexão ao explicitar como a organização da avaliação a partir da definição prévia de critérios e de resultados que se pretendem unívocos, concretos, precisos e objetivos se vincula a uma concepção reducionista de aprendizagem e de prática pedagógica, que se direciona fundamentalmente pelo que pode ser diretamente observável no comportamento do estudante. Esse modelo é adequado ao controle da eficiência do processo, porém, não conta com procedimentos capazes de tratar da aprendizagem como fenômeno complexo, constituído em muitas inter-relações que não podem ser desarticuladas.

Essa avaliação não trata de conhecer o processo vivido pelos estudantes, em suas aprendizagens. Busca os resultados e a partir deles faz inferências sobre o processo, segundo um padrão predefinido. Acredita-se que imprime precisão e eficiência à avaliação 
em decorrência dos objetivos (ou habilidades, no caso da Provinha Brasil) previamente estabelecidos como norteadores do ensino, o que gera processos de formação docente fundados no treinamento e na reprodução de procedimentos.

O autor critica as práticas que sustentam os exames em larga escala por induzirem processos pedagógicos mecanicistas, que reduzem o olhar docente sobre a aprendizagem e sobre o ensino, apoiados no pressuposto de existência de bases e princípios sólidos que podem ser automaticamente aplicados, levando ao aumento da proficiência dos estudantes nos exames, considerada expressão da aprendizagem. Em seu estudo aqui citado, contrapõe-se a essa proposição trazendo uma concepção de educação como processo criador que precisa buscar soluções para problemas complexos, para o que toma múltiplos fundamentos científicos e axiológicos e os utiliza de modo flexível na prática pedagógica, de modo que atenda as diferentes situações particulares que nela se evidenciam.

Tal enfoque não pretende enquadrar a ação, mas oferecer elementos para que docentes e discentes possam ordená-la, criativamente, por meio de um processo de compreensão da aprendizagem e do ensino. A melhora nas aprendizagens demanda melhor formação docente, o que implica ampliação das possibilidades de professores e professoras atuarem de acordo com a complexidade do processo pedagógico.

No mesmo sentido está o alerta de Afonso $(2007$, p. 20) sobre a relação entre avaliação externa e produção de uma educação de qualidade:

A adopção de certos dispositivos de avaliação externa (sobretudo os que são baseados em indicadores quantificáveis e mensuráveis) não contribuirá para a tão propagandeada melhoria da qualidade do ensino, representando antes um retrocesso político e educacional injustificável quando comparado com os progressos científicos e epistemológicos que têm vindo a conduzir a avaliação para perspectivas antipositivistas, mais complexas, pluralistas, democráticas e objetivas.

As vertentes críticas ajudam-nos a compreender a articulação da Provinha Brasil com a produção de resultados que diferenciam, para hierarquizar: contextos, processos, resultados e sujeitos. Essa é uma nova versão de procedimentos que pouco têm contribuído para o aprofundamento da dimensão democrática da escola.

A leitura cuidadosa do processo instaurado pela Provinha Brasil não a questiona como avaliação diagnóstica, porém indica o sentido classificatório do diagnóstico baseado em procedimento técnico vinculado a mensuração e produção de hierarquia. Há uma distribuição desigual das crianças, como efeito da classificação de seus diferentes conhecimentos/desempenhos segundo a escala usada, mantendo possibilidades de exercício do controle autoritário presente nas práticas hegemônicas de avaliação. $\mathrm{O}$ diagnóstico sustenta uma relação linear entre exame - investido de suas dimensões de coerção, certificação e exclusão - e aprendizagem, vista como aquisição de determinadas habilidades.

O diagnóstico, ato prioritariamente técnico, fortalece a individualização dos resultados e rasura o sujeito em sua potencial expressão da diferença. Essa avaliação diagnóstica não coloca em discussão práticas escolares que afastam os estudantes do conhecimento por desvalorizarem seus saberes, não reconhecerem como legítimos seus percursos de aprendizagem e/ou desconsiderarem a validade dos conhecimentos produzidos nos contextos socioculturais a que pertencem. Podemos inclusive observar no cotidiano escolar o fortalecimento de práticas e discursos que sequer tangenciam essa problemática e fazem 
do trabalho pedagógico um permanente treinamento para os exames estandardizados aos quais os estudantes serão submetidos, como expressa uma professora:

Estamos chegando perto da Provinha Brasil, mas antes a turma vai fazer o simulado. Então, parei o projeto e estamos treinando para a Provinha. Eu não quero que eles fiquem para trás. Estou usando o tempo da informática também... Alguns que não conseguem fazer as questões no papel acertam no computador. Mas eles precisam aprender a fazer no papel, senão, ficam para trás. Eu tenho que ensinar isso. Então, fico treinando. (Professora de turma de $2^{\circ}$ ano do ciclo)

O jogo enunciativo mobiliza um discurso que induz à necessidade de mais exame para se alcançar os objetivos ou metas traçados, tomados como equivalentes a aprendizagem e conhecimento necessários.

\section{FRATURAS}

A Provinha Brasil articula-se ao Plano Nacional de Educação (PNE) para o decênio 2011-2020, que apresenta como uma de suas metas "Alfabetizar todas as crianças até, no máximo, os oito anos de idade". Consoante à necessidade de verificação do alcance da meta se estabelecem os objetivos principais desse exame: "1. avaliar o nível de alfabetização dos alunos/turma nos anos iniciais do ensino fundamental; 2. diagnosticar possíveis insuficiências das habilidades de leitura e escrita" (Brasil, 2011).

A formulação clara e objetiva da meta não impede que nela se abrigue a mesma contradição que se entretece ao processo de escolarização no que se refere à democratização da educação escolar no Brasil: afirma o compromisso com a alfabetização de todos e cria condutas que impedem, ou ao menos dificultam, o cumprimento do compromisso. Ao estabelecer a alfabetização de todas as crianças como uma obrigação, reforça a democratização do processo de escolarização, entretanto, a meta mantém ativa a tensão inclusão/exclusão escolar quando demarca parâmetros uniformes de aprendizagem e desenvolvimento e determina um mesmo tempo para que todos cumpram o percurso definido como ideal. Considerando as grandes diferenças - sociais, históricas, culturais e individuais - que se entrecruzam aos processos de aprendizagem-ensino escolar e em especial da linguagem escrita, a padronização não pode eliminar os processos de exclusão que impedem a efetiva democratização da educação.

Retomando os objetivos anteriormente citados, vemos que integram a Provinha Brasil ao PNE e indicam os sentidos que o todos adquire nas políticas públicas e em práticas cotidianas. Revestem de coerência e objetividade a relação inclusão/exclusão/ democratização, tornando justa a distribuição desigual dos sujeitos diferentes, e ressignificam a impossibilidade inscrita na formulação da meta. O primeiro objetivo expõe o reconhecimento da diferença nas aprendizagens, que podem ser classificadas nos níveis predeterminados, embora nem todos sejam aceitáveis. O segundo objetivo lhe é complementar e traduz a diferença como insuficiência. Essa relação prevê resultados dissonantes que fazem que alguns não consigam se integrar ao todos. Assim, recorta o todos com os quais o Plano Nacional assume um efetivo compromisso de alfabetização, aos 8 anos, segundo os padrões estipulados. 
Obviamente, o diagnóstico precoce de insuficiências das habilidades de leitura e escrita visa sua imediata correção, mantendo a universalização da alfabetização como um objetivo a se atingir. A adequação à norma vigente permanece como condição para a integração da criança ao processo validado. O baixo desempenho da criança na Provinha Brasil sugere dúvidas sobre a sua capacidade para constituir-se como parte do todos com o qual se compromete o PNE.

Para atender à conformação do exame, reduz-se a linguagem para torná-la mensurável, o que leva a uma estreita percepção da prática pedagógica. As questões formuladas expressam uma concepção mecanicista de alfabetização, com conteúdo e método distantes do cotidiano de expressiva parcela dos estudantes, e expõem uma visão estereotipada dos conhecimentos, realidades e interesses infantis. A quantificação de acertos, buscados, e erros, inaceitáveis, sustenta a classificação dos estudantes. Para mostrar a proficiência requerida, a escola cada vez mais é levada a enfatizar práticas que podem aproximá-la do desempenho esperado, ainda que em detrimento da relação aprendizagem-ensino e desvitalizando o conhecimento.

O exame produz uma análise redutora dos resultados. Os múltiplos aspectos envolvidos no que se traduz como erro ou acerto e as respostas às perguntas da prova não se tornam objeto de reflexão. Apresenta-se a aprendizagem como movimento linear e progressivo, realizado em trajetória fixa e previsível e direcionado por um ensino baseado em prescrições que pretendem saber exatamente os pontos de partida e a quais pontos de chegada conduzirá os estudantes. Nesse projeto enrijecido de escolarização, a diferença dos sujeitos, culturas e contextos constituintes dos muitos percursos e resultados escolares adquirem um sentido negativo; não há espaço para desvios, lacunas, silêncios ou imobilidade, assumidos como evidências de insuficiências individuais a que se deve retificar.

A avaliação externa não evidencia a complexidade dos processos de aprendizagem-ensino e de uso da linguagem escrita, marcada pelo contexto social e não só pela vida escolar. O exame nacional apresenta como uma de suas principais finalidades a busca das insuficiencias, a partir dos níveis de desempenho, que informam sobre a adequação dos resultados ao processo de alfabetização reconhecido como válido. Ignora-se, na análise desses dados, as experiências das crianças como participantes de uma sociedade marcada, de modo desigual, pela cultura escrita. A aprendizagem é fraturada, descontextualizada e desvincula-se sua dimensão escolar das tantas outras dimensões cotidianamente vividas, nas quais são produzidos conhecimentos sobre a linguagem escrita, seus usos e suas interdições e também sobre o lugar de cada um como leitor e produtor de escrita. Participar, ainda que numa posição marginal, da cultura escrita faz da criança muito mais do que mera aprendiz de uma técnica de codificação e decodificação de mensagens.

O diagnóstico oferece informações que também sustentam prognósticos, de modo que o desempenho insuficiente no segundo ano de escolarização pode tornar-se indício de dificuldades posteriores no percurso escolar. Há muito se conhece na educação o Efeito Pigmalião e o quanto os resultados negativos dos estudantes correspondem à profecia autorrealizável; esse fenômeno pode ganhar impulso quando o diagnóstico isola o resultado do estudante do complexo contexto de sua produção, orientando as ações reparadoras exclusivamente para a criança, ressaltando suas impossibilidades.

Retomam-se concepções e justificativas amplamente conhecidas na educação brasileira que interpretam o fracasso escolar como o fracasso do sujeito na escola e 
não como o fracasso de um projeto de escola (Collares; Moysés, 1996; Patto, 1991), no qual não se criam espaços potentes para os diferentes sujeitos, com suas diferenças. As orientações presentes nos documentos oficiais que compõem o kit Provinha Brasil desconsideram, como uma das possibilidades de enfrentamento dos desempenhos insuficientes, o questionamento do conceito de alfabetização utilizado, do modelo de exame instituído, dos conhecimentos privilegiados, das metodologias indicadas, das condições estruturais da escola e da vida.

Diante da insuficiência, algumas perguntas são importantes no cotidiano escolar: o que sabem sobre a leitura e a escrita, para além das habilidades que o exame pretende verificar, as crianças classificadas nos níveis 1 e 2 , para as quais o documento recomenda especial atenção? Demonstram em suas atividades cotidianas os conhecimentos que o exame afirma que elas possuem, de acordo com a quantidade de suas respostas corretas? Que outros conhecimentos possuem? Como se inserem na cultura escrita? Como assumem a possibilidade de se apropriarem dessa linguagem?

Para refletir sobre essas questões, retomo o resultado da Provinha Brasil da turma que acompanhei durante um ano letivo e o comparo com atividades realizadas no cotidiano da sala de aula por crianças dessa turma e classificadas no nível 2. O Guia de correção e interpretação dos resultados afirma:

Como as crianças desse nível demonstram dominar a natureza alfabética do sistema de escrita, ou seja, reconhecem que as unidades menores da fala são representadas por letras, o professor precisa introduzir orientações para o domínio progressivo das regularidades e das irregularidades ortográficas da língua portuguesa. (Brasil, 2011, p.17)

Das três crianças classificadas nesse nível, duas não demonstram "dominar a natureza alfabética do sistema de escrita”, embora conheçam o alfabeto. São capazes de soletrar palavras, raramente conseguem lê-las, sabem de cor algumas sílabas, mas raramente as relacionam ao que pretendem escrever e encontram dificuldade para identificar uma mesma sílaba em diferentes palavras. Portanto, as considerações e sugestões partem de um princípio que não é verdadeiro para essas crianças; apoiada nele, a professora não é ajudada a perceber os conhecimentos que elas estão produzindo sobre a escrita nem a identificar as intervenções pedagógicas capazes de contribuir com suas aprendizagens.

Seguindo as descrições dos cinco níveis, a professora questiona os avanços percebidos nas crianças; como esses níveis são apresentados como parâmetros de uma aprendizagem normal, e não como um movimento possível entre tantos outros, permitem a conclusão de que essas crianças não estão aprendendo, o que serve como indicador de alguma anormalidade nelas. Essa certamente é uma resposta insuficiente para a suposta "não aprendizagem", pois não basta a existência de um esquema de classificação, ainda que descreva os comportamentos ou habilidades esperados. É preciso ir mais fundo e criar procedimentos que ajudem a conhecer: os trajetos realizados para a produção dos resultados apresentados, as aprendizagens que conduzem às respostas consideradas insuficientes ou os diferentes conhecimentos que dialogam com os ensinamentos escolares.

O exame não pode responder a essas demandas, seus resultados servem à distribuição dos estudantes numa escala e proporcionam justificativas socialmente aceitas para a articulação entre baixo desempenho, ausência de aprendizagem e de conhecimentos 
válidos, desigualdade dos resultados escolares e posicionamento do sujeito à margem do processo aceito. "Insuficiência" (ou mesmo "distorção") é o termo que conecta a identificação da diferença à justificativa da desigualdade, o que vincula a avaliação à gestão da desigualdade e de seus efeitos, escolares e sociais. A consolidação do exame nacional para crianças articula-se à possibilidade de sua manutenção na escola em um contexto de inclusão degradada (Martins, 1997), em que a ideia de todos está marcada por um variado conjunto de exclusões, necessárias à normalização, e protegido por um impreciso conceito de inclusão.

A normalização atua sobre a linguagem escrita, produzindo efeitos na produção da subjetividade e na aprendizagem, já que, segundo Geraldi (2010, p. 123-124):

A linguagem, enquanto processo de constituição da subjetividade, marca as trajetórias individuais dos sujeitos que se fazem sociais também pela língua que compartilham. A exploração das contrapalavras das compreensões diferentes permite o cálculo de horizontes de possibilidades e a construção, através da memória do futuro, de lugares desterritorializados a partir dos quais podem ser mobilizados desejos e ações que, respeitando diferenças, não as transformam em desigualdades.

A avaliação estandardizada não dá lugar à contrapalavra ao fazer da diferença um signo da desigualdade. Sem contrapalavra não há libertação, não se criam espaços de realização da potencialidade da diferença e não se pode superar o processo de subalternização. O modelo de avaliação externa em vigor desconsidera que a aprendizagem não se limita ao indivíduo, sua realização liga-se a ações contextualizadas, fortemente vinculadas à dinâmica cultural. A polarização que o modelo único alimenta dificulta a percepção do ensino e da aprendizagem como processos dialógicos, que se constituem mutuamente. A avaliação realiza-se como um ato exterior à relação pedagógica: verifica, mensura, julga, classifica e prescreve. Atua em consonância ao processo social de silenciamento dos sujeitos, saberes e culturas periféricos, ofuscando os processos de negação da liberdade através da inferiorização e desumanização dos grupos que diferem da norma (Dussel, 2006; Mignolo, 2003).

A proposta de elevação do rendimento escolar como efeito da regulação promovida pelo sistema de exames e como um procedimento indutor da redução das desigualdades sociais desconsidera a complexa dinâmica de produção/manutenção dos processos de subalternização. O debate sobre o papel da escolarização na dinâmica social precisa considerar o potencial transformador da escola por algumas das experiências que proporciona e por muitos dos conhecimentos que disponibiliza (sem dúvida, o acesso à escrita está entre eles), e ver a escola como um importante espaço social de regulação da alteridade, por meio da valoração das identidades fixas e estáveis, nas quais também se enquadram os estereótipos e estigmas, que conformam o padrão considerado válido e, consequentemente, negam os comportamentos que dele diferem.

As concepções de aprendizagem, alfabetização e avaliação presentes na Provinha Brasilmostram-se especialmente prejudiciais às crianças que encontram no conhecimento escolar um elemento articulador de sua participação em uma sociedade imersa na cultura escrita. Considerando as condições em que vivem as crianças das classes populares, suas experiências nas periferias urbanas participando de grupos postos à margem dos direitos sociais, muitas vezes em condições de vida degradadas,é previsível que apresentem, dentro 
de um mesmo período e segundo os mesmos parâmetros, desempenhos diferentes dos alcançados por crianças que cotidianamente partilham em suas interações extraescolares conhecimentos, modelos cognitivos e valores reconhecidos como positivos pela escola.

A produção da desigualdade e sua legitimação demandam o reconhecimento da singularidade e da pluralidade, pois a visualização da diferença é necessária à ordenação e ao controle que buscam diluir sua potência transformadora. A negação da diferença orienta uma dinâmica excludente, portanto indesejada quando se pretende uma escola pública democrática, a favor das classes populares em sua histórica luta contra a subalternização e em busca da libertação.

\section{RASURAS}

A Provinha Brasil tem ampla divulgação pela mídia. Em um dos filmes veiculados, uma menina afirma: "Eu já sei ler e escrever.Mas o que vai dizer se eu aprendi mesmo...É a Provinha Brasil". Essa apresentação chama-me a atenção por tirar da escola a possibilidade de reconhecimento e, portanto, de avaliação, dos resultados do seu próprio trabalho. Embora a menina afirme saber ler e escrever, esse reconhecimento não é resultado de sua percepção e da avaliação docente, mas do exame externo. $\mathrm{O}$ deslocamento da ação docente no processo avaliativo reafirma-se na proposta oficial:

Um instrumento elaborado para oferecer aos professores e aos gestores das escolas públicas e das redes de ensino um diagnóstico do nível de alfabetização dos alunos, ainda no início do processo de aprendizagem, permitindo, desse modo, intervenções visando à correção de possíveis insuficiências apresentadas nas áreas de leitura e escrita. (Brasil, 2009, p. 6)

Sigo na reflexão, focalizando o tipo de informação que a Provinha Brasil proporciona aos docentes e o processo pedagógico que pretende fomentar. Considerando que a prova, segundo os documentos oficiais, verifica apenas alguns dos "eixos" nos quais se agrupam as habilidades consideradas "imprescindíveis para o desenvolvimento da alfabetização e do letramento", cabe indagar como se verificarão as habilidades dos eixos não contemplados no exame e os motivos que levam a permitir aos docentes a responsabilidade pela avaliação de algumas habilidades imprescindíveis, mas não de todas. Também me parece importante observar como se integram, no cotidiano escolar, informações obtidas por meio de diferentes procedimentos de avaliação: Provinha Brasil e instrumentos produzidos na escola.

A prova e os demais documentos que formam o kit Provinha Brasil evidenciam seu caráter pragmático, redutor, por focalizar exclusivamente um conjunto de habilidades. Ficam fora do diagnóstico as dimensões cultural, social e política da alfabetização e a natureza ética da educação, o que fragiliza sua possibilidade de produzir orientações para a prática que contribuam para uma alfabetização em seu sentido mais profundo que, como há tanto tempo nos ensina Paulo Freire, coloque em articulação a leitura da palavra e a leitura de mundo. $\mathrm{O}$ foco em um conjunto restrito de habilidades sem estabelecer conexões com a palavramundo limita a relação aprendizagem-ensino, muitas vezes distanciando o estudante, sujeito que aprende, do conhecimento, suposto objeto da aprendizagem. 
Como as outras habilidades, não verificadas por esse instrumento, compõem a percepção docente sobre as crianças, como alfabetizadas ou não, e se incorporam ao processo pedagógico pautado pela classificação das crianças em níveis? Um exame, cujo resultado se traduz em níveis, pode pretender-se não classificatório? O que esse exame mostra? O que oculta?

As questões do exame desconsideram o que não pode ser traduzido em descritores, formatado em perguntas e respostas unívocas, categorizado e mensurado. Os resultadoshierarquicamente ordenados -, segundo os documentos, expõem as principais habilidades necessárias à alfabetização desenvolvida por cada criança. Embora os documentos reafirmem que a Provinha não substitui a avaliação docente, é importante interrogar como se percebe a entrada da Provinha nas salas de aula, nas escolas e em cada município.

Não se pode separar a Provinha, mesmo lembrando sua intenção não classificatória, do ranqueamento, da classificação e da premiação (que não têm sentido sem seu par, mesmo que oculto, o castigo). Tampouco é possível ignorar as relações entre o desempenho dos estudantes nos exames e a distribuição oficial de recursos e benefícios para as escolas. Em nome de uma intenção, não se pode retirar do debate os desdobramentos que a política produz nos municípios em relação ao reconhecimento de profissionais e/ou escolas, de acordo com os desempenhos dos estudantes nos diferentes exames externos a que são submetidos, sua interferência na vida escolar ou os significados que adquire para professores, professoras e estudantes.

Nesse contexto, a avaliação da aprendizagem realizada como parte do processo pedagógico tem sua relevância reduzida em relação à classificação das crianças produzida com base em seus desempenhos na Provinha Brasil.É preciso trazer à reflexão, como um de seus efeitos, a segregação de crianças que se distanciem nos níveis de desempenho almejados.

As questões que compõem o teste, sua correção, e a classificação (segregação, sua indesejável(?) parceira) dos estudantes, a interpretação dos resultados e a proposição de desdobramentos pedagógicos - formulada fora do contexto escolar - dirão quem está alfabetizado. A Provinha Brasil acompanha tendência percebida em outros exames estandardizados, inseridos em processos de avaliação externa, de reduzir as margens da autonomia docente, pelos mecanismos de controle ao qual se vincula, inclusive no que se refere ao planejamento cotidiano da prática pedagógica. $\mathrm{O}$ grau de regulação indica desconfiança sobre a capacidade docente de formulação e de compreensão de sua prática cotidiana.

Recentemente ouvi de duas professoras de escolas, municípios, estados e regiões diferentes, a mesma palavra ao falar dos resultados dos exames externos: bumilhação. Obviamente a quantidade de "informantes" é inexpressiva, mas o sentimento é forte, não pode ser desconsiderado na reflexão sobre as políticas de avaliação da alfabetização.

Na pesquisa que coordeno, para além do desconforto docente, temos observado discrepâncias entre a classificação de algumas crianças na Provinha e as habilidades que demonstram em suas atividades escolares cotidianas, mesmo se tomarmos como única referência os descritores oficiais. Essa discrepância é verificada entre os estudantes que não atingem o nível esperado para o ano de escolarização que estão cursando (como vimos na situação anteriormente discutida) e entre os que apresentam uma boa aprendizagem, compatível com seu percurso escolar. 
Para prosseguir com a reflexão, trago um resultado que nos leva a ter no nível 3 tanto uma criança que lê palavras soltas, encontrando dificuldade naquelas consideradas mais complexas por terem dígrafos, encontros consonantais ou encontros vocálicos e algumas vezes não se mostrando capaz de ler frases curtas, quanto outra que lê com razoável fluência, oral e silenciosamente, livros de literatura infantil, estabelece relação entre unidades sonoras e suas representações gráficas, localiza informações explícitas no texto e reconhece seu assunto.

Segundo o resultado da Provinha Brasil, nessa turma, crianças que cotidianamente demonstram diferenças expressivas nos usos que fazem da leitura e da escrita estão classificadas no mesmo nível. Do mesmo modo, crianças que em suas atividades diárias apresentam conhecimentos semelhantes são classificadas em níveis distintos. ${ }^{3} \mathrm{Nas}$ atividades da pesquisa, com diferentes professoras alfabetizadoras atuando em diferentes contextos, encontro situações semelhantes.

Considerando que se pretende um diagnóstico para a elaboração de um plano de trabalho, orientado pelos documentos que compõem o kit Provinha Brasil, de acordo com o nivelamento proposto, a professora que se encontra nessa situação pode ter grandes dificuldades para definir sua ação com as crianças. Tais situações expõem, mais uma vez, a impossibilidade de se encaixarem crianças reais, em seus processos múltiplos de interação com a cultura escrita, como parte de suas atividades escolares cotidianas, em classificações organizadas a partir de uma criança abstrata e de uma linguagem restrita, consideradas universais.

Uma das possibilidades para lidar com essas situações é a professora ou o professor passar a desconfiar de sua avaliação sobre os estudantes e não do instrumento usado, que também poderia ser problematizado. A desconfiança docente sobre sua avaliação e não sobre a avaliação externa pode ser motivada por um discurso de desqualificação docente que ganha força em nossa sociedade e também pelas várias propostas locais de estímulo ao aumento do desempenho, que muitas vezes chegam a interferir no valor do salário recebido. Cabe perguntar qual é o peso da avaliação docente, na instituição, quando difere do resultado da Provinha, e quais têm sido as intervenções dos setores de acompanhamento pedagógico de cada escola e das secretarias de educação no intuito de levar o desempenho da turma aos níveis considerados ideais. Crescem os relatos de "simulados de Provinha Brasil" nas escolas, de treinamento das crianças para a realização da prova objetiva, cujo modelo passa a orientar as atividades cotidianas.

Casos como esses evidenciam que as bases em que se realiza o diagnóstico não favorecem a incorporação dos parâmetros e argumentos utilizados à reflexão da escola sobre o processo pedagógico. Esse diagnóstico mostra-se pouco produtivo para uma compreensão mais complexa da prática docente e das relações que estabelece com as aprendizagens das crianças. Simultaneamente, a correlação entre qualidade da aprendizagem e número de acertos na prova induz ao questionamento sobre o que fazer com as crianças que, por muito que se faça para enquadrá-las no desenvolvimento desejável, ou normal, não elevam seu nível de desempenho; ou o que dizer da professora ou do professor que mesmo tendo sua formação continuada orientada pelos vários documentos

3 Na turma em questão, 21 alunos, dos 23 que a frequentam, fizeram a Provinha, e a professora discorda da classificação de pelo menos seis deles. 
que compõem o kit e que tenha desenvolvido as atividades propostas, não consegue fazer que alguns de seus alunos "progridam".

Não ignoro a existência de potência e limites no conhecimento e na ação docentes e sublinho que a complexidade dos processos cotidianos exige formação continuada a partir de um questionamento intenso sobre a própria prática. Mas, a adesão a um modelo sem problematizar o exame, incluindo seu marco interpretativo, como vetor de uma política e articulado em bases teórico-epistemológicas assinaladas ao longo deste texto, dificulta a compreensão de que por seu intermédio o que se pode obter são fragmentos do processo de aprendizagem e dos conhecimentos da criança. Quando se infere a qualidade da aprendizagem infantil - seus processos e resultados -, a partir de pequenos fragmentos aos quais se atribui valor de totalidade, corre-se o risco de se distanciar os resultados verificados da própria criança, invisibilizada como sujeito que faz percursos singulares, relacionados a suas experiências socioculturais nos coletivos dos quais participa.

O desempenho e a classificação atuam de modos diversos sobre os sujeitos. Entretanto, não podemos minimizar o papel que o exame cumpre como uma estratégia de disseminação e detalhamento de saber e de poder sobre o outro. Mais uma vez tocamos o debate sobre os sentidos da política de avaliação instituída, pois, quando no lugar do exame estabelecemos práticas dialógicas de avaliação, outros são os resultados alcançados e de outros modos se interpretam os processos. Quando as crianças têm voz na sala de aula, também são capazes de avaliar a si próprias e a dinâmica pedagógica; nesses momentos, sempre se podem perceber importantes aprendizagens e o muito que conhecem sobre a escrita, inclusive aqueles que apresentam desempenhos insuficientes nos exames.

A avaliação estandardizada fortalece a configuração de lugares menores aonde encaminhar o outro - aquele que não corresponde ao modelo idealizado, referência de desempenho a se alcançar, portanto ele próprio sujeito menor, reduzido em suas potencialidades, expressão do desvio, da impossibilidade. Produz-se uma narrativa socialmente válida sobre o outro, justificando a desqualificação da alteridade, num movimento que diminui a possibilidade e o direito de o sujeito narrar-se a partir de suas próprias experiências, culturas e valores. Esse processo fragmenta relações, isola sujeitos e distancia-os de seus próprios processos, desvalorizados diante dos resultados esperados. A segregação implícita no exame mantém-se e produz espaço para a criação de outras possibilidades de exercício de poder autoritário, tradicionalmente presente na avaliação e inscrito nos mecanismos de controle que sustentam os procedimentos usados.

Os níveis de desempenho dão visibilidade à singularidade dos sujeitos e à pluralidade de sentidos e caminhos presentes no cotidiano da sala de aula; encontram a diferença para torná-la alvo dos mecanismos de ordenação e controle com a finalidade de negar sua legitimidade. Em nome de uma escola de qualidade, materializam a tradução da diferença em desigualdade ao produzirem lugares legitimamente desiguais onde inscrever as crianças. Qualidade a ser posta em discussão, já que a dinâmica instituída cria obstáculos para práticas dialógicas, no processo de alfabetização, fundamentais a um permanente processo de ampliação de conhecimentos por todos.

A relação entre a aplicação de uma "provinha" e a garantia da alfabetização das crianças no máximo aos 8 anos de idade expressa a permanência de uma perspectiva redutora da infância, aliada a concepções mecanicistas de alfabetização e de avaliação. Olha-se a criança como uma subjetividade menor, uma cidadania menor. Redução que 
também atinge a professora ou o professor, responsável, por vezes, pela aplicação e correção da prova, nunca por sua elaboração e pela interpretação de seus resultados.

Neste ponto, é interessante retomar o diálogo com Geraldi (s.d., p. 16) em sua discussão sobre a proposta oficial de alfabetização e seus desdobramentos na vida social:

Agora se tranquiliza a escola e a manutenção do status quo desta sociedade: há o que ensinar nos primeiros anos de escolaridade: uma técnica (e há um método a ser implantado, o método fônico) e um sentido (o reconhecimento do já dado, do previsto).Ler e escrever jamais seriam revolucionários nesta cidade do letramento ou letramentos, já que este prevê de antemão o lugar social que cada qual deve ocuparqualquer exceção pode ser inadequada, quer sejam uma leitura e uma escrita para mais (política e crítica), quer sejam uma leitura e uma escrita para menos (escrever com erros ou não compreender instruções, avisos, faturas, contas, receitas etc. gêneros discursivos tão presentes no neotecnicismo das sequências didáticas de ensino dos gêneros discursivos).

A política de avaliação expõe uma concepção acrítica, apolítica e conformista de alfabetização; a técnica, o sentido único e o discurso unívoco coordenam os processos. A reflexão sobre as propostas de uniformização das práticas e dos resultados escolares ressalta relações dessa política com os movimentos de conformação e manutenção de uma estrutura de poder colonial (Mignolo, 2003). O poder colonial, estruturado pela colonialidade do poder, do saber e do ser, atua no discurso pedagógico para o silenciamento de parcelas da sociedade e de determinadas culturas, expostas como inaceitáveis. ${ }^{4}$

A escolarização, parte das relações de colonialidade, traz algumas de suas características marcantes, apresentadas por Dussel (2006): produz todas as demais culturas como periféricas, regula a alteridade, desqualifica a cultura popular e favorece a subalternidade. O insucesso escolar, parte desse discurso, é um dos artefatos de produção de invisibilidade e incompreensão, ou seja, de inexistência, de conhecimentos e de formas de aprender que não correspondem à perspectiva hegemônica.

$\mathrm{O}$ fracasso do estudante na escola relaciona-se à negação do outro, sujeito que expõe fraturas do projeto hegemônico e oculta a circunscrição do restrito projeto de democratização da escola aos processos sócio-históricos de subalternização. A dimensão social do fracasso escolar não elimina a relevância da prática pedagógica em sua configuração, sendo a avaliação um de seus componentes, embora ressalte sua produção como uma demanda de uma sociedade desigual que individualiza resultados para produzir imagens convenientes às práticas que marginalizam diversos grupos sociais.

$\mathrm{O}$ projeto de qualidade da educação vigente fundamenta-se em processos de exclusão que reafirmam padrões inacessíveis a todos e adequados a apenas um pequeno segmento da sociedade brasileira, assim guardando vínculos com fracasso escolar. A concepção de qualidade em vigor inscreve-se em um discurso de desqualificação da escola pública como espaço de produção e socialização de conhecimentos válidos. Os resultados dos exames nacionais com frequência evidenciam os baixos índices dos estudantes das

4 Uma discussão sobre as relações do poder colonial com a avaliação da aprendizagem pode ser encontrada em Esteban, 2010. 
escolas públicas, ocupantes das piores posições nos rankings produzidos. Sua análise é superficial, a ela não se integram dados relativos às condições oferecidas às escolas públicas, às desigualdades socioeconômicas entre estudantes dos distintos segmentos sociais que ocupam as diversas faixas de desempenho, às opções teórico-epistemológicas na condução do currículo e dos exames estandardizados, mais uma vez favoráveis aos setores mais elitizados da população e distantes das classes populares.

Os resultados aferidos induzem à conclusão de que a escola pública pouco pode fazer no sentido de garantir que todas as crianças e todos os jovens ampliem seus conhecimentos, já que constantemente apresentam maus resultados. ${ }^{5} \mathrm{~A}$ Provinha Brasil não tem seus resultados apresentados em rankings nacionais, embora já se tenha notícias de secretarias de educação que difundem seus resultados na rede, permitindo, e estimulando, classificações e comparações entre docentes de uma mesma escola e/ ou escolas da mesma rede de ensino. Seu resultado atua para conformar os sujeitos a procedimentos pedagógicos ajustados à concepção de qualidade hegemônica, mais vinculada às demandas do mercado do que às exigências socioculturais da maioria da população.

A relação inclusão/exclusão escolar é importante na articulação da subalternidade, mesmo quando se elevam alguns índices de aferição do desempenho estudantil. Cabe olhá-la com cuidado. A política de avaliação da alfabetização, como parte do projeto educacional, induz as práticas escolares à reprodução, à simplificação, sempre redutora das possibilidades de criação e de exercício de autonomia. Os processos de normalização e de controle, traduzidos em uniformização curricular, com estabelecimento de conteúdos mínimos, padronização metodológica, nivelamento de desempenhos e avaliação classificatória, norteiam a relação pedagógica. Predominam no discurso da e sobre a escola, jogando para suas margens sujeitos, culturas, práticas e processos subalternizados. A diferença, uma das questões fundamentais da experiência humana, também evidente no cotidiano escolar, desqualifica-se quando se torna, através de procedimentos pedagógicos, justificativa para a desigualdade.

\section{CALEIDOSCÓPIO}

Da perspectiva teórico-epistemológica em que me situo, os exames nacionais estandardizados, com sua potência de controle e uniformização, não atendem às necessidades das classes populares, que buscam a democratização do conhecimento como instrumento de sua histórica luta por libertação. A parcial conquista pelas classes populares de seu direito à escola não pode ser apagada e traduzida como concessão. Suas demandas trazem o diálogo com as margens socioculturais para o centro da reflexão sobre a composição do currículo, seu desdobramento nas práticas escolares cotidianas e a dinâmica de avaliação implementada. Tais aspectos são parte de uma reflexão que pode contribuir para aprofundar o percurso de democratização que a escola, entre grandes contradições,

5 Recentemente uma aluna relatou fato ocorrido na escola onde trabalha, durante a reunião com os responsáveis pelos estudantes: uma mãe pediu a palavra e perguntou "por que na escola pública é proibido ensinar às crianças". 
vem vivendo, para entretecê-la à produção da razão subalterna ${ }^{6}$ pela ressignificação dos seus próprios sentidos e dos seus processos cotidianos.

Esse projeto só pode articular-se pelo diálogo, que abre possibilidades para que a heterogeneidade de percursos, processos, conhecimentos, valores e projetos se incorporem ao projeto educacional escolar. Para isso, é preciso que as práticas cotidianas se sustentem em perspectivas paradigmáticas que assumem a complexidade do processo pedagógico e tomam o conhecimento como produção sociocultural, contextualizada e significativa, tecida pela diferença e pela igualdade de direitos. O diálogo fortalece a vocação da escola para ser um espaço democrático em que a relação aprendizagem-ensino se exerce como parte da dinâmica intercultural.

As crianças têm direito a experimentar, numa escola fundamentada no diálogo, a dimensão intersubjetiva do conhecimento, um espaço de criação e imprevisibilidade. A Provinha Brasil não pode colaborar com esse projeto, já que restrição ao diálogo e desqualificação da heterogeneidade são dois de seus pilares essenciais.

As práticas escolares cotidianas são potenciais articuladoras de relações ancoradas na diferença cultural, que promovem a ampliação do acesso de todos ao conhecimento, como produção humana coletiva. $O$ processo de avaliação pode integrar-se a esse movimento, por meio de práticas fundamentadas na interação, no diálogo, na reflexão, em que erro e acerto não são posições com valores desiguais, mas expressões dos diferentes sujeitos, processos e conhecimentos que dialogam na produção de novas possibilidades, de saber e de fazer.

O exame, com seus procedimentos de generalização, classificação e encobrimento das singularidades, desvincula-se dos projetos de escolarização críticos à subalternização. A avaliação como prática coletiva que integra os diferentes sujeitos escolares na reflexão sobre o vivido, sobre os percursos realizados e sobre o muito que ainda se pode percorrer se mostra um processo relevante na dinâmica aprendizagem-ensino em articulação aos processos sociais que conjugam democracia e libertação. Ao criticar os exames estandardizados, não me coloco contra a avaliação, pelo contrário, compartilho com outros a defesa da potencialidade de uma avaliação feita por todos numa escola pública que se deseja de todos.

\section{REFERÊNCIAS}

Afonso, Almerindo. Estado, políticas educacionais e obsessão avaliativa. Contrapontos, Itajaí, Programa de Pós-Graduação da UNIVALI, v. 7, n. 1, p. 11-22, jan./abr. 2007.

Bнавна, Homi. O local da cultura. Belo Horizonte: UFMG, 1998.

BRASIL. MEC/INEP. Provinha Brasil: passo a passo. Brasilia, MEC/INEP, 2009.

. Provinha Brasil: guia de correção e de interpretação de resultados. Disponível em:

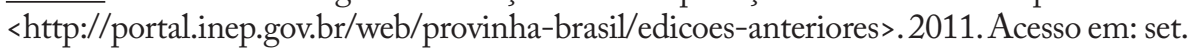
2011.

6 Segundo Mignolo (2003, p. 160), a razão subalterna articula "novas formas de racionalidade, emergindo de experiências subalternas" com impactos "tanto para a autocompreensão quanto para as políticas públicas, que criam condições para transformar (e estigmatizar) as relações de subalternidade". 
Ceale - Centro de Alfabetização, Leitura e Escrita. Letra A: O Jornal do Alfabetizador, Faculdade de Educação, Universidade Federal de Minas Gerais, Belo Horizonte, 2008.

Collares, Cecília; Moysés, Maria Aparecida. Preconceitos no cotidiano escolar: ensino e medicalização. São Paulo: Cortez, 1996.

Díaz Barriga, Ángel.Uma polêmica em relação ao exame.In: Esteban, Maria Teresa (Org.). Avaliação: uma prática em busca de novos sentidos. Rio de Janeiro: DP\&A, 1999.

Dusses, Enrique. Ética de la liberación: en la edad de la globalización y de la exclusión.Madrid: Trotta, 2006.

Esteban, Maria Teresa; Afonso, Almerindo (Orgs.). Olhares e interfaces: reflexões críticas sobre a avaliação. São Paulo: Cortez, 2010.

Fals Borda, Orlando. Aspectos teóricos da pesquisa participante. In: Brandão, Carlos Rodrigues (Org.). Pesquisa participante. 3. ed. São Paulo: Brasiliense, 1983.

Fernandes, Domingos. Avaliação das aprendizagens: desafios às teorias, práticas e políticas. São Paulo: Editora da UNESP, 2009.

Foucault, Michael. Vigiar e punir. Petrópolis: Vozes, 1997.

Freire, Paulo. Pedagogia do oprimido. Rio de Janeiro: Paz e Terra, 2005.

Garcia, Regina Leite (Org.). Método. Métodos. Contramétodo. São Paulo: Cortez, 2003.

Geraldi,João Wanderley. Ancoragens: estudos bakhtinianos. São Carlos: Pedro e João Editores, 2010.

- Alfabetização e letramento: perguntas de um alfabetizado que lê. S.d. Disponível em: <www.moodle.ufba.br/mod/resource/view.php?id=97328>. Acesso em: set. 2010.

Gimeno SaCristán, José. La pedagogia por objetivos: obsesión por la eficiencia. Madrid: Morata, 1997.

IBGE - Instituto Brasileiro de Geografia e Estatística. Sintese de indicadores sociais: uma análise das condições de vida da população brasileira. Rio de Janeiro, IBGE, 2010.

Martins, José de Souza. A exclusão social e a nova desigualdade. São Paulo: Paulus, 1997.

Mignolo, Walter. Histórias locais/projetos globais. Belo Horizonte: Editora da UFMG, 2003. Patto, Maria Helena Souza. A produção do fracasso escolar. São Paulo: T. A.Queiroz, 1991.

Santos Guerra, Miguel Ángel. Tornar visivel o quotidiano: teoria e prática da avaliação qualitativa nas escolas. Porto: Asa, 2003.

Saul, Ana Maria. Avaliação emancipatória. São Paulo: Cortez, 1991.

StoвarT, Gordon. Tiempos de prueba: los usos e abusos de la evaluación.Madrid:Morata,2010.

\section{SOBRE A AUTORA}

Maria Teresa Esteban é doutora em filosofia e ciências da educação pela Universidade de Santiago de Compostela. Professora da Universidade Federal Fluminense (UFF).

E-mail:mtesteban@uol.com.br 


\section{MARIA TERESA ESTEBAN}

\section{Considerações sobre a política de avaliação da alfabetização: pensando a partir do cotidiano escolar}

O artigo trata das políticas de avaliação da alfabetização com base na Provinha Brasil, para refletir sobre os sentidos que a avaliação vem adquirindo no contexto das políticas públicas e no cotidiano escolar. $\mathrm{O}$ trabalho desenvolve-se a partir de pesquisa com o cotidiano escolar articulada à pesquisa-ação participante. As relações estabelecidas entre os processos instaurados e resultados obtidos nas esferas macro e microestruturais tornam necessária a indagação das relações que se produzem entre as políticas instituídas e a construção de processos favoráveis às aprendizagens de todas as crianças. Com base na vertente crítica no campo da avaliação educacional e na teoria pós-colonial, problematiza a avaliação em larga escala, contrapõe exame a avaliação e discute processos que possam dar efetiva contribuição à alfabetização das crianças das classes populares.

Palavras-chave: avaliação; alfabetização; cotidiano escolar. 


\section{Considerations about the literacy assessment policies: thinking the daily school life}

This article discusses the assessment policies of literacy, using Provinha Brazil, to reflect on the senses that the assessment has been gaining in the context of public policies and in daily school life. The work has been developed from research with the daily school life articulated with participatory action research. The relations established between the processes and results in macro and microstructural spheres make it necessary to question the relations produced between the established policies and the construction of processes favorable to the learning of all children. Based on the critical movement in the field of educational assessment and on the postcolonial theory, it problematizes large-scale assessment, contrasts examination and assessment and discusses processes that can effectively contribute to the literacy of the working class children.

Keywords: assessment; literacy; daily school life.

\section{Consideraciones respecto a la política de evaluación de la alfabetización: pensando a partir de la vida escolar cotidiana}

El artículo trata de las políticas de evaluación de la alfabetización, a partir de la Provinha Brasil, con el fin de reflexionar respecto a los sentidos que la evaluación ha adquirido en el contexto de las politicas públicas y en la vida escolar cotidiana. El trabajo se desarrolla a partir de investigación con el cotidiano escolar articulada con la investigación-acción participativa. Las relaciones que se establecen entre los procesos instaurados y los resultados obtenidos en las esferas macro e micro estructurales hacen necesario el cuestionamiento de las relaciones que se producen entre las politicas instituidas y la construcción de procesos favorables a los aprendizajes de todos los niños y niñas. Se fundamenta en la vertiente crítica en el campo de la evaluación educacional y en la teoría postcolonial para problematizar la evaluación a través de pruebas estandarizadas, contraponer examen a evaluación y discutir procesos que contribuyan con la alfabetización efectiva de los niños y niñas de las clases populares.

Palabras clave: evaluación; alfabetización; cotidiano escolar. 